\section{GIANT, TOOTHED PLATYPUS CRUSHED ITS PREY}

A new and extinct, toothed species of platypus, the largest of its kind, has been discovered in the Riversleigh world heritage area in Queensland, Australia, ${ }^{1}$ contradicting the previous presumption that the modern edentate platypus could be traced back to ancient fossil species by a single, direct lineage.

A morphologically distinctive lower molar was found embedded in limestone, revealing an unknown branch of the platypus's evolution: the Obdurodon tharalkooschild, a much larger species with a distinct dental formation, though featuring stunted roots, anteroposterior compression of the crown and column-like primary buccal cusps similar to other toothed platypuses from the Obdurodon genus. With unique lophid and cusp relations, food was transversely masticated between the upper and lower molars. Prey will have included soft-bodied aquatic animals, as well as small vertebrates such as frogs and baby turtles. Apical cusp wear on the teeth suggest the extinct Obdurodon tharalkooschild crushed rather than cut its hard prey. These functional teeth, so unlike the dentally degenerate set the modern platypus is initially born with, suggests this new species belonged to a divergent group.

The tooth, dating between 5 and 15 million years old, is younger than the most ancient members of the platypus family, which spans 61 million years, but is the first in a previously unknown lineage of extinct giant platypuses.

1. Pian $R$, Archer M, Hand S J. A new, giant platypus, Obdurodon tharalkooschild, SP. Nov. (Monotremata, Ornithorhynchidae) from the Riversleigh world heritage area, Australia. J Vertebr Paleonto/ 2013; 33: 1255-1259.

By Laura Pacey

\section{PLANT GROWS IN MAN'S TOOTH}

A video has emerged on YouTube from Next Media Animation News Direct depicting a 36-year-old Taiwanese man who had a guava sprout growing in a decayed third molar. The tooth was removed by a dentist and it was estimated that the sprout was about ten days old.

www.youtube.com/

watch?v=omqjAyuoFfI

\section{PLAIN PACKAGING PUSH}

In response to the news that fewer smokers are using the NHS in England to try to quit smoking, Chief Executive of the British Dental Health Foundation, Dr Nigel Carter OBE, highlighted the importance of smoking cessation services. 'The rise in people successfully quitting is encouraging,' he said, '[but] if we want to really make a difference to the number of people who kick the habit, introducing plain packaging on tobacco products is a must.'

\section{GDC ARF AND CPD DUE}

The General Dental Council (GDC) has written to all dentists to remind them to pay their annual retention fee (ARF) and to make a continuing professional development (CPD) declaration.

The ARF collection period and CPD declaration period for dentists began on 12 November 2013. The $£ 576$ ARF (and £76 specialty fee where registered) are due by 31 December 2013 for the 2014 registration year. A list of dentists who fail to make the payment by this time will be sent to Father Christmas ... the NHS, Health Boards and indemnity providers to enable them to keep their records up to date.

Dentists who are required to submit CPD for 2013 have until 28 January 2014 to make a declaration. Visit www.eGDC-uk.org to make a payment or submit CPD.

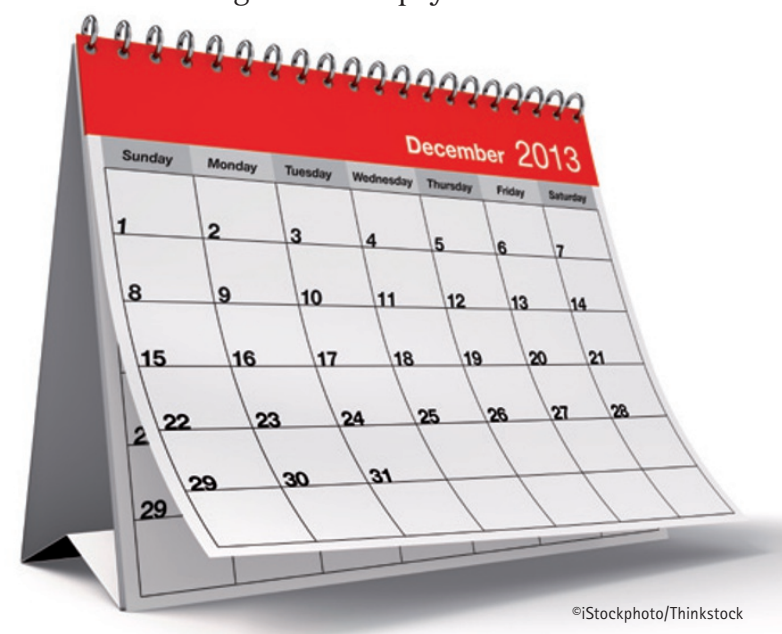

\section{DIARY}

ESAO Conference: How to practise aesthetic orthodontics safely, ethically and legally as a GDP Date: 14 December 2013

Venue: RCOG, London

http://esao.co.uk/event-registration/

Essences of Anterior Implant Aesthetics:

The Perio-Ortho-Restorative Connection (1996-2014)

Date: 18 January 2014 Telephone: 02084875555 www.adi.org.uk/janmasterclass 2014

BDA Seminar: White, whiter, whitest: successful strategies for predictable teeth whitening

Date: 31 January 2014

Venue: BDA, Wimpole Street, London

Email:events@bda.org

Telephone: 02075634590

www.bda.org/seminars

Oral-B Up To Date seminar Date and location: 13 February 2014, Bristol; 27 February 2014, Plymouth; 13 March 2014, Warrington; 27 March 2014, Newcastle

Telephone: 07585508550 Email:julia@ab-communications. com

www.dentalcare.com

IDEM Singapore - International Dental Exhibition and Meeting Date: 3-6 April 2014 Venue: SUNTEC Convention and Exhibition Centre, Singapore www.idem-singapore.com

British Dental Conference \& Exhibition 2014

Date: 10-12 April 2014

Venue: Manchester Central Convention Complex, Manchester www.bda.org/conference

Clinical Innovations

Conference 2014

Date: 14-15 May 2014

Venue: Kings Place, King's Cross, London

Telephone: 02074008989 Email: info@healthcare-learning. com 